\title{
Design of a large-scale femtoliter droplet array for single-cell analysis of drug-tolerant and drug-resistant bacteria
}

\author{
Ryota lino ${ }^{1,2}$ *, Yoshimi Matsumoto ${ }^{3}$, Kunihiko Nishino ${ }^{3}$, Akihito Yamaguchi ${ }^{4,5}$ and Hiroyuki Noji,2 \\ ${ }^{1}$ Department of Applied Chemistry, Graduate School of Engineering, The University of Tokyo, Tokyo, Japan \\ ${ }^{2}$ Core Research for Evolutional Science and Technology, Japan Science and Technology Agency, Tokyo, Japan \\ ${ }^{3}$ Laboratory of Microbiology and Infectious Diseases, Institute of Scientific and Industrial Research, Osaka University, Osaka, Japan \\ ${ }^{4}$ Department of Cell Membrane Biology, Institute of Scientific and Industrial Research, Osaka University, Osaka, Japan \\ ${ }^{5}$ Graduate School of Pharmaceutical Sciences, Osaka University, Osaka, Japan
}

\section{Edited by:}

Jun Lin, The University of Tennessee, USA

Reviewed by:

Shigetoshi Eda, University of

Tennessee, USA

Ahmad S. Khalil, Boston University,

USA

Aldo Jesorka, Chalmers University of

Technology, Sweden

\section{*Correspondence:}

Ryota lino, Department of Applied

Chemistry, Graduate School of

Engineering, The University of Tokyo,

7-3-1 Hongo, Bunkyo-ku, Tokyo, Japan

e-mail: iino@appchem.t.u-tokyo.ac.jp
Single-cell analysis is a powerful method to assess the heterogeneity among individual cells, enabling the identification of very rare cells with properties that differ from those of the majority. In this Methods Article, we describe the use of a large-scale femtoliter droplet array to enclose, isolate, and analyze individual bacterial cells. As a first example, we describe the single-cell detection of drug-tolerant persisters of Pseudomonas aeruginosa treated with the antibiotic carbenicillin. As a second example, this method was applied to the single-cell evaluation of drug efflux activity, which causes acquired antibiotic resistance of bacteria. The activity of the MexAB-OprM multidrug efflux pump system from Pseudomonas aeruginosa was expressed in Escherichia coli and the effect of an inhibitor D13-9001 were assessed at the single cell level.

Keywords: single-cell analysis, microdevice, drug tolerance, persister, drug resistance, drug efflux, transporter

\section{INTRODUCTION}

Opportunistic infection with bacteria resistant to multiple antibiotics is a continuing clinical challenge (Taubes, 2008). The antibiotic resistance of bacteria can be classified into two categories, natural resistance (tolerance) and acquired resistance. In natural resistance, a very small proportion of the bacterial population is resistant to multiple antibiotics despite having the same genotype as the sensitive majority. These bacteria are often referred to as "persisters" (Lewis, 2010). However, the nature of these persisters is not fully understood because they occur at a very low frequency in a bacterial population (typically less than $1 \%$ ), which makes systematic studies difficult (Allison etal., 2011; Balaban, 2011, Gerdes and Maisonneuve, 2012; Kint etal., 2012). In the first section of this review article, we describe a microdroplet-based method to identify and culture individual bacterial cells for efficient detection of persisters. In contrast, acquired antibiotic resistance is caused by a change in the genotype of the sensitive strain. The four main mechanisms of acquired resistance are suppression of drug influx into the cell due to decreased expression of membrane channel proteins, inactivation of drugs by intracellular and extracellular enzymes, mutations in the target proteins of drugs, and active efflux of the drugs from the cell due to increased expression of efflux pumps (Fischbach and Walsh, 2009; Nikaido, 2009). Here we focused on the active efflux of drugs from the cell. In the second section, we introduce a microdroplet-based method for assessing the drug efflux activity of single bacterial cells.

\section{ADVANTAGES OF SINGLE-CELL ANALYSIS USING A MICRODEVICE}

Single-cell analysis is a powerful approach for detecting variations among the cells in a population, such as differences in the expression of proteins, the copy number of genes, and the concentration of metabolites (Li and Xie, 2011; Trouillon et al., 2013). Single-cell analysis can overcome the limitations associated with ensembleaveraged data from multiple cells, and enable the identification of very rare cells with properties that differ from those of the majority. Microfabricated devices have contributed greatly to the development of massively parallel and high-throughput single-cell analyses.

However, in most microdevices, the target cells are eukaryotic, such as mammalian cells and yeasts (Sims and Allbritton, 2007; Gupta et al., 2010, Lindstrom and Andersson-Svahn, 2010), because their size, a few millimeters to tens of micrometers, allows for easy handling compared to bacteria, which are much smaller in size. Thus far, only a few studies have used microdevices for single bacterial cell analysis (Balaban et al., 2004; Cai etal., 2006, Ottesen et al., 2006; Weibel etal., 2007, Boedicker etal., 2009; Teng etal., 2013, Wakamoto et al., 2013). In addition, in many microdevices that are based on microfluidic channels and valves or droplets generated in a microfluidic channel, the closed nature of the system makes the collection of cells from the device and their subsequent use difficult. Therefore, the development of microdevices from which individual bacterial cells can be recovered has been highly anticipated. 


\section{LARGE-SCALE FEMTOLITER DROPLET ARRAY FOR SINGLE BACTERIAL CELL ANALYSIS}

We recently developed a micron-sized femtoliter droplet array fixed on a hydrophilic-in-hydrophobic micropatterned surface (Sakakihara et al., 2010). In our new microdevice, a large number of dome-shaped femtoliter droplets can be prepared that enclose individual bacterial cells (Iino et al., 2012a). One prominent feature of this array is that the individual droplets containing the enclosed cells can be accessed and collected with a micropipette. The array can also be used for mass culture and gene and protein analyses.

We prepared the hydrophilic-in-hydrophobic micropatterned surface through conventional microfabrication (Figure 1A). A hydrophobic polymer of carbon-fluorine (CYTOP; Asahi Glass, Japan) was deposited on $\mathrm{a} \mathrm{SiO}_{2}$ cover glass, and photolithography was performed using a high-viscosity photoresist. The resistpatterned substrate surface was dry-etched with $\mathrm{O}_{2}$ plasma by using a reactive ion-etching system to produce circular micropatterns on a hydrophilic $\mathrm{SiO}_{2}$ glass surface. The diameter of the exposed hydrophilic $\mathrm{SiO}_{2}$ surfaces was $10-30 \mu \mathrm{m}$, and they were surrounded by a hydrophobic polymer layer with a height of $1 \mu \mathrm{m}$. A fabricated micropatterned cover glass was attached to the bottom of a perforated petri dish (Figure 1B). The circular micropatterns were grouped into islands and were numbered

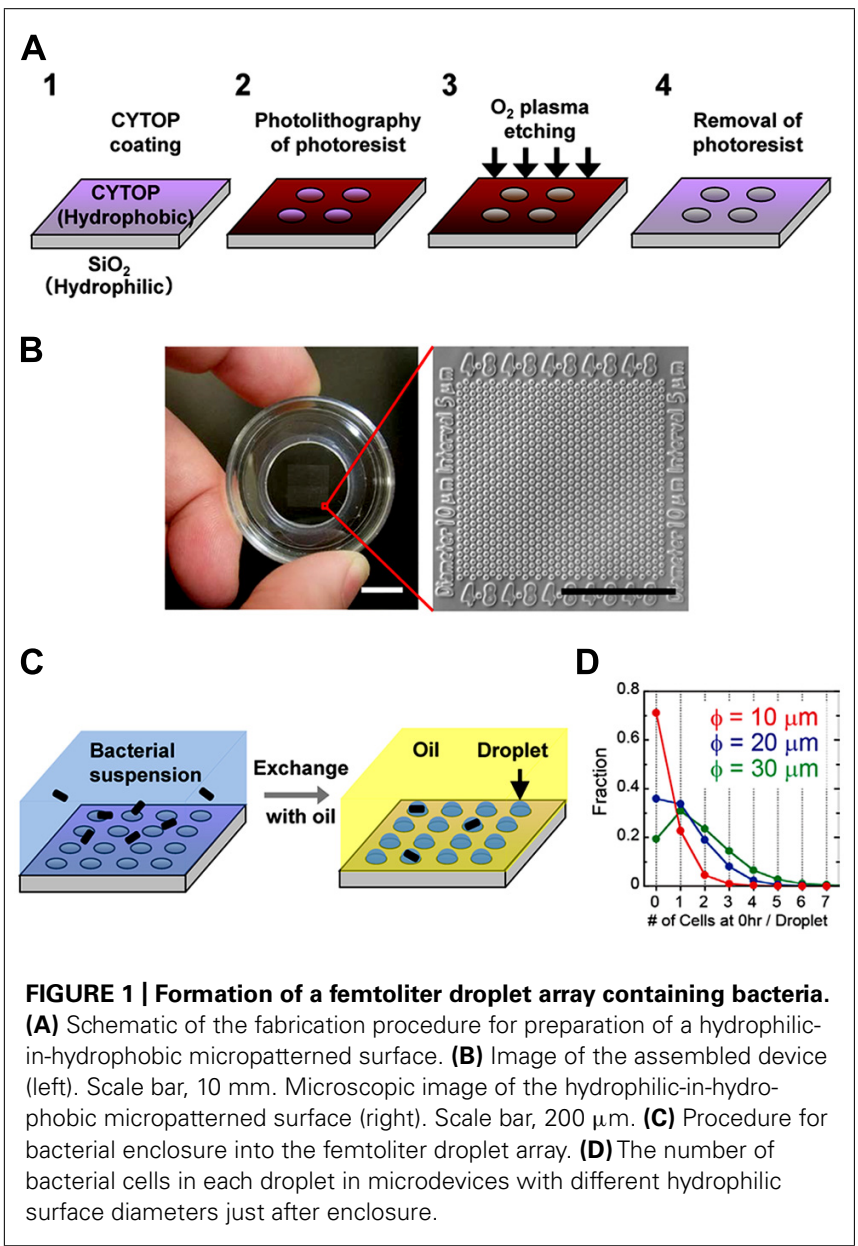

to identify the individual droplets and the cells enclosed in each droplet.

To form a droplet array containing bacteria, we covered the micropatterned cover glass with medium containing a bacterial suspension (Figure 1C, left). Then, fluorinated oil (Fluorinert FC40; Sigma Aldrich, USA), which has a higher density than water, was flowed over the medium near the surface. The hydrophilic $\mathrm{SiO}_{2}$ glass surfaces retained the medium and the bacteria, whereas the hydrophobic surface was replaced with oil. As a result, many droplets containing one or more bacteria were formed (Figure 1C, right). More than $3 \times 10^{5}$ droplets could be simultaneously prepared in a $1-\mathrm{cm}^{2}$ area in a single device. Enclosure of the cells in the droplets was stochastic and was dependent on the cell density of the bacterial suspension. At an optical density (turbidity) at $600 \mathrm{~nm}\left(\mathrm{OD}_{600}\right)$ of 0.6 , approximately $20-30 \%$ of the droplets contained single cells. Increasing the diameter of the hydrophilic surfaces to 20 or $30 \mu \mathrm{m}$ increased the fraction of droplets containing multiple cells; however, the fraction of droplets containing single cells did not increase significantly (Figure 1D). In contrast, the number of droplets formed increased significantly when we used a device with hydrophilic surfaces of a smaller diameter. Therefore, to increase the total number of droplets containing single cells, we used a microdevice containing hydrophilic surfaces with a diameter of $10 \mu \mathrm{m}$.

\section{DETECTION OF PERSISTER BACTERIA IN A FEMTOLITER DROPLET ARRAY}

We generated a femtoliter droplet array of Pseudomonas aeruginosa PAO1 using our microdevice to detect persisters under an optical microscope. In the control experiment without antibiotic treatment, most cells underwent multiple cell divisions after incubation overnight at $37^{\circ} \mathrm{C}$ (Figures 2A,B). The divided cells showed active flagellar motion, indicative of high metabolic activity. To detect persisters, an antibiotic, carbenicillin (at final concentration of $5 \mathrm{mg} / \mathrm{mL}$, which is $\sim 100$ times higher than the minimal inhibitory concentration), was added to the bacterial suspension that was grown to late exponential phase $\left(\mathrm{OD}_{600} \sim 1.0\right)$ in trypticase soy broth. The suspension was further incubated at $37^{\circ} \mathrm{C}$ for $3 \mathrm{~h}$, and then the cells were collected, washed, resuspended in fresh medium $\left(\mathrm{OD}_{600} \sim 0.2\right)$. This suspension was enclosed in a droplet array. After enclosure, the whole device was placed in an incubator at $37^{\circ} \mathrm{C}$, and the cells were cultured overnight. The persisters were easily identified under an optical microscope the overnight culture (Figure 3A). The divided cells were not cells that acquired resistance, but were actually persisters. This was confirmed by collecting the cells with a micropipette with an aperture diameter of 10-15 $\mu \mathrm{m}$ (Figures 3B,C), inoculating a culture in test tubes, and antibiotic susceptibility testing.

Bacterial cells that divided multiple times were counted, and the frequency of persisters was calculated. The frequency of persisters in the femtoliter droplet array $(1.5 \pm 0.72 \%, N=4$; Figure 3D) was quite unexpectedly much higher than that estimated by conventional agar plate assays $(0.10 \pm 0.03 \%, N=4)$. In the plate assays, the carbenicillin-treated preculture sample was prepared as described above along with an untreated culture sample, and then the samples were serially diluted and cultured overnight at $37^{\circ} \mathrm{C}$ on agar plates. The number of colonies on the plates 


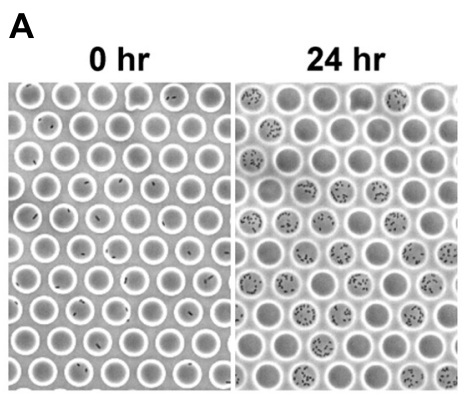

B

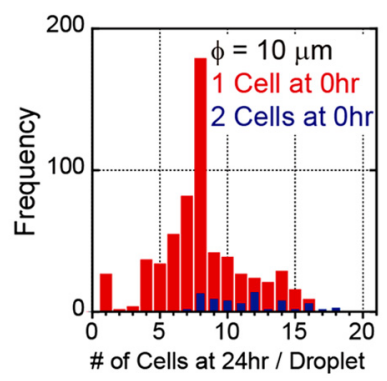

FIGURE 2 | Enclosure and culture of bacteria in a femtoliter droplet array. (A) Images of $P$. aeruginosa PAO1 after $0 \mathrm{~h}$ (left) and $24 \mathrm{~h}$ (right) of culture in the femtoliter droplet array. (B) Distribution of the number of cells after $24 \mathrm{~h}$ of culture.

from carbenicillin-treated and untreated preculture samples were counted and compared. It has been recently reported that quorum sensing autoinducer increased the frequency of persister appearance (Moker et al., 2010; Leung and Levesque, 2012, Vega et al., 2012), and that inhibiting the quorum signal restored antibiotic susceptibility (Pan et al., 2012, 2013). Furthermore, the quorumsensing signal could be transduced even in single isolated cells when PAO1 was enclosed in picoliter-volume droplets (Boedicker et al., 2009). Therefore, enclosure of a single cell in a femtoliter droplet may enhance the quorum sensing signal and increase persister frequency. The effect of the quorum sensing signal on the frequency of persister appearance in the femtoliter droplet array can be more clearly confirmed by treating the cells with antibiotic after enclosure in the droplets by adding the antibiotic with a micropipette (Sakakihara et al., 2010).

\section{A SINGLE-CELL DRUG EFFLUX ASSAY IN A FEMTOLITER DROPLET ARRAY}

The AcrAB-TolC multicomponent efflux pump system recognizes and expels a wide variety of compounds, including antibiotics, dyes, and detergents. In this system, AcrA is the membrane fusion protein that stabilizes the complex (Zgurskaya and Nikaido, 1999), AcrB is the inner membrane transporter protein that belongs to the resistance-nodulation-division (RND) family (Murakami et al., 2006; Nakashima et al., 2011, 2013), and TolC is the outer membrane channel protein (Koronakis et al., 2000). The AcrAB-TolC efflux system is responsible for both intrinsic and acquired drug resistance of Gram-negative bacteria such as Escherichia coli and Salmonella enterica (Nishino and Yamaguchi, 2008; Nikaido and Takatsuka, 2009). Two systems $P$. aeruginosa that are homologous

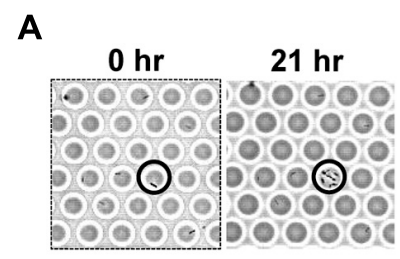

B

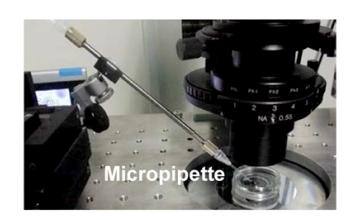

C

D
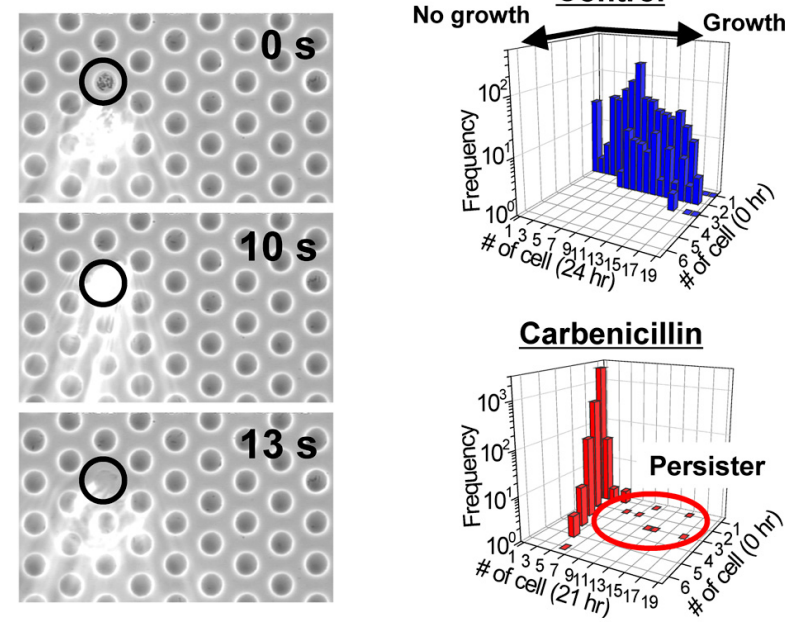

FIGURE 3 | Detection of the persisters in the femtoliter droplet array. (A) Images of $P$. aeruginosa PAO1 persisters (indicated by circle) after $0 \mathrm{~h}$ (left) and $21 \mathrm{~h}$ (right) of culture in the femtoliter droplet array. (B) Image of the micropipette used for droplet collection. (C) Sequential images of droplet collection. (D) Distribution of the number of cells in each droplet before and after overnight culture. Top, control cells without carbenicillin treatment. Bottom, carbenicillin-treated cells.

to the AcrAB-TolC system, MexAB-OprM and MexXY-OprM, lead to multidrug resistance in clinical isolates (Morita et al., 2001; Livermore, 2002; Hocquet et al., 2006, 2007; Henrichfreise et al., 2007).

We have recently developed a single-cell drug efflux assay using the femtoliter droplet array (Figure 4; Iino et al., 2012a). In this assay, E. coli cultured in test tubes was mixed with a fluorogenic substrate, fluorescein-di- $\beta$-D-galactopyranoside (FDG), enclosed in a droplet array, and then cultured for 15-20 $\mathrm{min}$ at room temperature. Upon entering the cytoplasm of E. coli, FDG is hydrolyzed into the fluorescent dye fluorescein by $\beta$-galactosidase. Both FDG and fluorescein are substrates for the AcrAB-TolC system (Matsumoto et al., 2011; Iino et al., 2012b). In wild-type cells, FDG was effectively pumped out before hydrolysis, and no fluorescence was detected (Figure 4A, left, and Figure 4B, top). In contrast, when FDG was imported into $\triangle a c r B(\Delta B)$ and $\triangle$ tolC $(\Delta \mathrm{C})$ strains it was hydrolyzed to fluorescein. In $\Delta \mathrm{B}$ cells, not only the cells, but also the droplets themselves fluoresced (Figure 4A, center, and Figure 4B, middle) because the remaining minor RND efflux pumps slowly pumped out the fluorescein. Although only a small amount of the dye was pumped out, it could be easily detected because it was confined to the femtoliter droplet (Rondelez et al., 2005; Sakakihara et al., 2010, Kim et al., 2012). In $\Delta \mathrm{C}$ cells, fluorescein accumulated in the cell (Figure 4A, right, and 


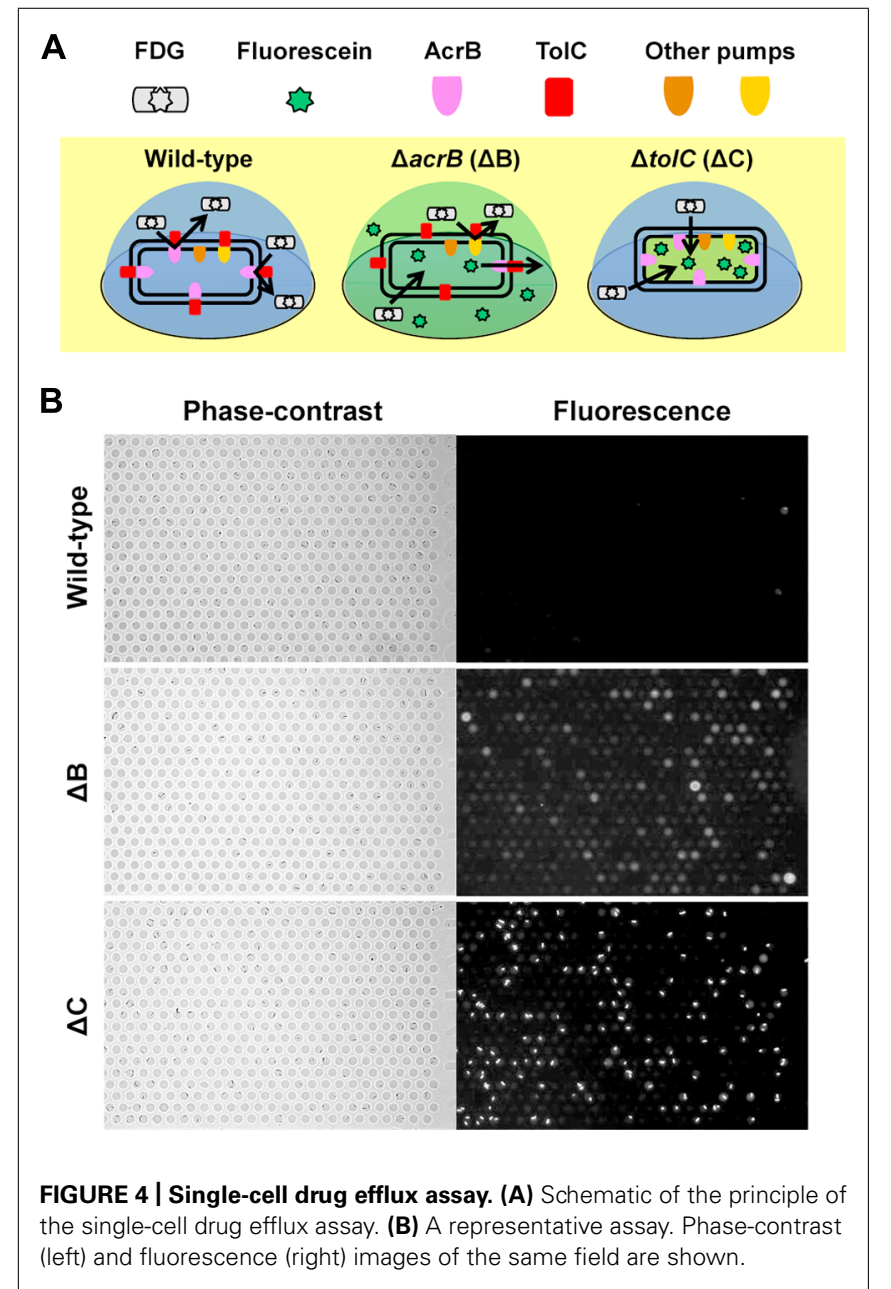

Figure $4 \mathrm{~B}$, bottom) because TolC is a channel protein common to both the major and minor RND efflux pumps in E. coli.

With this method, the inhibitory effect of chemical compounds against the efflux pump can be easily assessed. The effect of an efflux pump inhibitor, D13-9001 (Yoshida et al., 2007), is shown in Figure 5. D13-9001 has been reported to enhance the antibacterial activities of several antibiotics by binding tightly to the drug binding pockets of AcrB and MexB (Nakashima et al., 2013). A $\Delta \mathrm{B} \Delta \mathrm{C}$ double-knockout $E$. coli strain that stably expresses MexAB-OprM from $P$. aeruginosa was used for the experiment. This strain did not fluoresce in our assay, indicating that the exogenously expressed MexAB-OprM worked well in E. coli, and that the cells recovered drug efflux activity (Figure 5, top). Addition of D13-9001 increased the number of fluorescent cells (Figure 5, bottom). The fluorescence intensity of the cells increased as the concentration of D13-9001 increased, indicating a concentration-dependent inhibitory effect. D13-9001 is a specific inhibitor of MexB, a major efflux pump in $P$. aeruginosa. However, it does not inhibit MexY, which is another major efflux pump in P. aeruginosa (Yoshida et al., 2007). Our simple and rapid approach would be useful to screen for new inhibitors that are also effective against MexY and other efflux pumps.

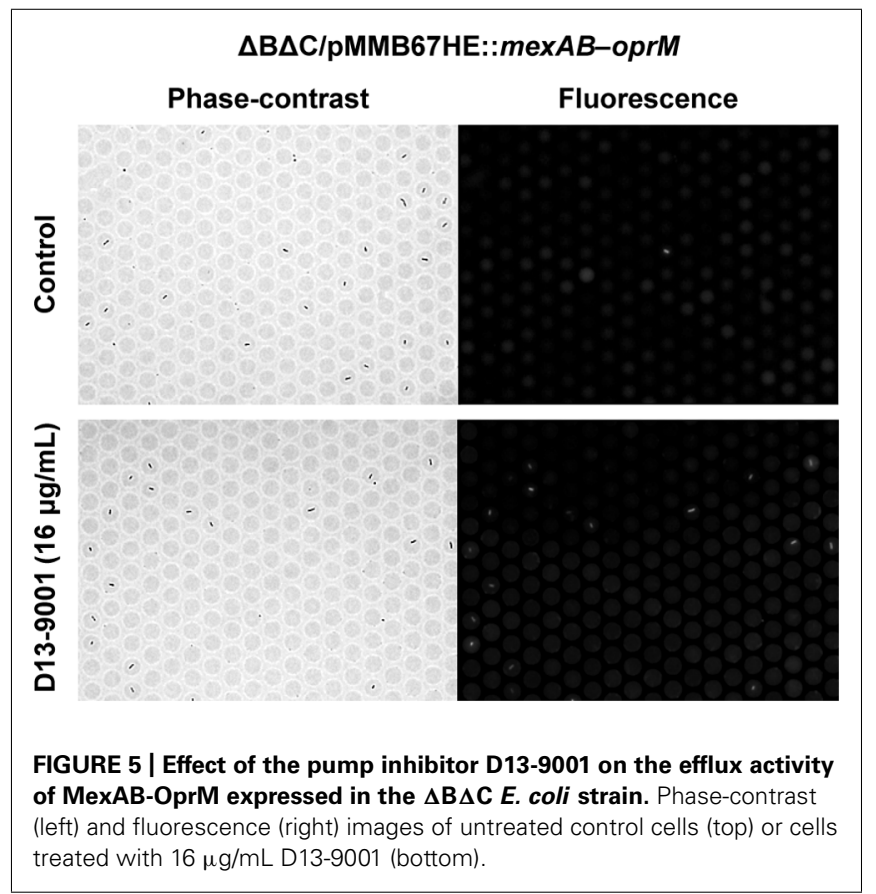

\section{PHENOTYPIC CHANGE AFTER GENETIC TRANSFORMATION}

As a demonstration of the rapid phenotypic change after genetic transformation, we introduced the $S$. enterica tolC gene into E. coli $\Delta \mathrm{C}$ cells. After electroporation with the expression vector, the cells were incubated for different time durations in the presence of the selection marker kanamycin and drug efflux activity was assessed. The efflux-active phenotype was observed after $3 \mathrm{~h}$ (Figure 6, top), whereas no phenotypic change was observed in the control experiment (Figure 6, bottom).

A prominent feature of the femtoliter droplet array is the ability to access individual droplets. Using a micropipette, not only droplets but also the cells within the droplets can be collected (Figures 3B,C). Collected single cells divide multiple times after

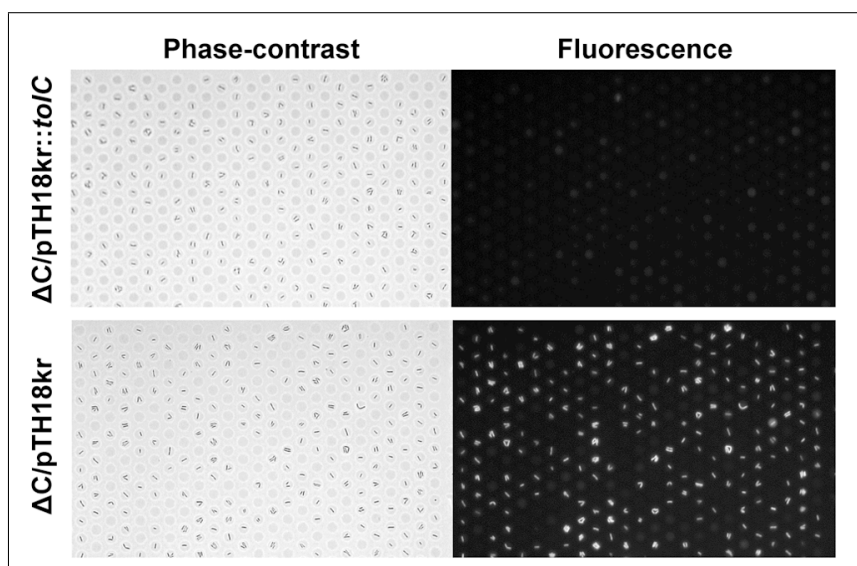

FIGURE 6 | Phenotypic change after genetic transformation.

Phase-contrast (left) and fluorescence (right) images of $E$. coli $\Delta \mathrm{C}$ cells transformed with a vector expressing tolC from Salmonella enterica (pTH18kr::tolC; top) or a control vector pTH18kr (bottom). 
transfer to growth medium in a test tube. The plasmid in the divided cells can be extracted and used for subsequent gene analysis (Iino et al., 2012a). Culturing after cell collection can be omitted by amplifying the DNA by single-cell PCR (Ottesen et al., 2006). Considering the rapid detection $(3 \mathrm{~h})$ of the phenotypic change after genetic transformation, single-cell gene analysis would enable high-throughput screening.

\section{PERSPECTIVE}

As described above, the femtoliter droplet array is useful for singlebacterial cell analysis. Single-cell analysis of persister bacteria could help elucidate the mechanism of persister appearance and the reversible switching dynamics between persister and sensitive

\section{REFERENCES}

Allison, K. R., Brynildsen, M. P., and Collins, J. J. (2011). Heterogeneous bacterial persisters and engineering approaches to eliminate them. Curr. Opin. Microbiol. 14, 593-598. doi: 10.1016/j.mib.2011.09.002

Balaban, N. Q. (2011). Persistence: mechanisms for triggering and enhancing phenotypic variability. Curr. Opin. Genet. Dev. 21, 768775. doi: 10.1016/j.gde.2011.10.001

Balaban, N. Q., Merrin, J., Chait, R., Kowalik, L., and Leibler, S. (2004). Bacterial persistence as a phenotypic switch. Science 305, 1622-1625. doi: $10.1126 /$ science. 1099390

Boedicker, J. Q., Vincent, M. E., and Ismagilov, R. F. (2009). Microfluidic confinement of single cells of bacteria in small volumes initiates highdensity behavior of quorum sensing and growth and reveals its variability. Angew. Chem. Int. Ed. Engl. 48, 59085911. doi: 10.1002/anie.200901550

Cai, L., Friedman, N., and Xie, X. S. (2006). Stochastic protein expression in individual cells at the single molecule level. Nature 440, 358-362. doi: 10.1038/nature04599

Fischbach, M. A., and Walsh, C. T. (2009). Antibiotics for emerging pathogens. Science 325, 1089-1093. doi: 10.1126/science. 1176667

Gerdes, K., and Maisonneuve, E. (2012). Bacterial persistence and toxinantitoxin loci. Annu. Rev. Microbiol. 66, 103-123. doi: 10.1146/annurevmicro-092611-150159

Gupta, K., Kim, D. H., Ellison, D., Smith, C., Kundu, A., Tuan, J., et al. (2010). Lab-on-a-chip devices as an emerging platform for stem cell biology. Lab Chip 10, 2019-2031. doi: 10.1039/c004689b

Henrichfreise, B., Wiegand, I., Pfister, W., and Wiedemann, B. (2007). Resistance mechanisms of multiresistant pseudomonas aeruginosa strains from Germany and correlation with Hypermutation del.
Antimicrob. Agents Chemother. 51, 4062-4070. doi: 10.1128/aac.0014s07

Hocquet, D., Nordmann, P., El Garch, F., Cabanne, L., and Plesiat, P. (2006). Involvement of the MexXYOprM efflux system in emergence of cefepime resistance in clinical strains of Pseudomonas aeruginosa. Antimicrob. Agents Chemother. 50, 13471351. doi: 10.1128/AAC.50.4.13471351.2006

Hocquet, D., Roussel-Delvallez, M., Cavallo, J. D., and Plesiat, P. (2007). MexAB-OprM- and MexXY-overproducing mutants are very prevalent among clinical strains of Pseudomonas aeruginosa with reduced susceptibility to ticarcillin. Antimicrob. Agents Chemother. 51, 1582-1583. doi: 10.1128/AAC.01334-06

Iino, R., Hayama, K., Amezawa, H., Sakakihara, S., Kim, S. H., Matsumono, Y., et al. (2012a). A singlecell drug efflux assay in bacteria by using a directly accessible femtoliter droplet array. Lab Chip 12, 39233929. doi: 10.1039/c2lc40394c

Iino, R., Nishino, K., Noji, H., Yamaguchi, A., and Matsumoto, Y. (2012b). A microfluidic device for simple and rapid evaluation of multidrug efflux pump inhibitors. Front. Microbiol. 3:40. doi: 10.3389/fmicb. 2012.00040

Kim, S. H., Iwai, S., Araki, S., Sakakihara, S., Iino, R., and Noji, H. (2012). Large-scale femtoliter droplet array for digital counting of single biomolecules. Lab Chip 12, 49864991. doi: 10.1039/c2lc40632b

Kint, C. I., Verstraeten, N., Fauvart, M., and Michiels, J. (2012). New-found fundamentals of bacterial persistence. Trends Microbiol. 20, 009

Koronakis, V., Sharff, A., Koronakis, E., Luisi, B., and Hughes, C. (2000). Crystal structure of the 577-585. doi: 10.1016/j.tim.2012.08.

cells. This single-cell drug efflux assay can be used to screen for pump inhibitors, which requires the testing of numerous compounds. Our method is a direct evaluation of efflux activity, it takes only 20-30 min, and its advantage over the conventional method, based on the shift in the minimal inhibitory concentration is evident. Furthermore, with the advantage of individual droplet accessibility, single persister cells and cells exhibiting the efflux-active phenotype can be easily collected and used for subsequent analysis. It should be possible to screen for genes encoding functional efflux pump systems with a plasmid library of cloned genomic fragments. We believe that our approach will aid in addressing the challenge of infectious diseases caused by bacteria that are multidrug tolerant and resistant.

bacterial membrane protein TolC central to multidrug efflux and protein export. Nature 405, 914-919. doi: $10.1038 / 35016007$

Leung, V., and Levesque, C. M. (2012). A stress-inducible quorumsensing peptide mediates the formation of persister cells with noninherited multidrug tolerance. J. Bacteriol. 194, 2265-2674. doi: 10.1128/JB.067 07-11

Lewis, K. (2010). Persister cells. Annu. Rev. Microbiol. 64, 357-372. doi: 10. 1146/annurev.micro.112408.134306

Li, G. W., and Xie, X. S. (2011). Central dogma at the single-molecule level in living cells. Nature 475, 308-315. doi: 10.1038/nature10315

Lindstrom, S., and Andersson-Svahn, H. (2010). Overview of single-cell analyses: microdevices and applications. Lab Chip 10, 3363-3372. doi: $10.1039 / \mathrm{c} 0 \mathrm{lc} 00150 \mathrm{c}$

Livermore, D. M. (2002). Multiple mechanisms of antimicrobial resistance in Pseudomonas aeruginosa: our worst nightmare? Clin. Infect. Dis. 34 , 634-640.

Matsumoto, Y., Hayama, K., Sakakihara, S., Nishino, K., Noji, H., Iino, R., et al. (2011). Evaluation of multidrug efflux pump inhibitors by a new method using microfluidic channels. PLOS ONE 6:e18547. doi: 10.1371/journal.pone.0018547

Moker, N., Dean, C. R., and Tao, J. (2010). Pseudomonas aeruginosa increases formation of multidrugtolerant persister cells in response to quorum-sensing signaling molecules. J. Bacteriol. 192, 1946-1955. doi: 10.1128/JB.01231-09

Morita, Y., Kimura, N., Mima, T., Mizushima, T., and Tsuchiya, T. (2001). Roles of MexXY- and MexABmultidrug efflux pumps in intrinsic multidrug resistance of Pseudomonas aeruginosa PAO1. J. Gen. Appl. Microbiol. 47, 27-32.

Murakami, S., Nakashima, R., Yamashita, E., Matsumoto, T., and Yamaguchi, A. (2006). Crystal structures of a multidrug transporter reveal a functionally rotating mechanism. Nature 443, 173-179. doi: 10.1038/nature05076

Nakashima, R., Sakurai, K., Yamasaki, S., Hayashi, K., Nagata, C., Hoshino, K., et al. (2013). Structural basis for the inhibition of bacterial multidrug exporters. Nature 500, 102-106. doi: 10.1038 /nature 12300

Nakashima, R., Sakurai, K., Yamasaki, S., Nishino, K., and Yamaguchi, A. (2011). Structures of the multidrug exporter AcrB reveal a proximal multisite drug-binding pocket. Nature 480, 565-569. doi: 10.1038 /nature 10641

Nikaido, H. (2009). Multidrug resistance in bacteria. Annu. Rev. Biochem. 78, 119-146. doi: 10.1146/ annurev.biochem.78.082907.145923

Nikaido, H., and Takatsuka, Y. (2009). Mechanisms of RND multidrug efflux pumps. Biochim. Biophys. Acta 1794, 769-781. doi: 10.1016/j.bbapap.2008.10.004

Nishino, K., and Yamaguchi, A. (2008). Role of xenobiotic transporters in bacterial drug resistance and virulence. IUBMB Life 60, 569-574. doi: 10.1002/iub.90

Ottesen, E. A., Hong, J. W., Quake, S. R., and Leadbetter, J. R. (2006). Microfluidic digital PCR enables multigene analysis of individual environmental bacteria. Science 314, 1464-1467. doi: 10.1126/science. 1131370

Pan, J., Bahar, A. A., Syed, H., and Ren, D. (2012). Reverting antibiotic tolerance of Pseudomonas aeruginosa PAO1 persister cells by (Z)-4-bromo-5(bromomethylene)-3-methylfuran-2 (5H)-one. PLoS ONE 7:e45778. doi: 10.1371/journal.pone.0045778

Pan, J., Song, F., and Ren, D. (2013). Controlling persister cells of $\mathrm{Pseu}$ domonas aeruginosa $\mathrm{PDO} 300$ by (Z)-4-bromo-5-(bromomethylene)- 
3-methylfuran-2(5H)-one. Bioorg. Med. Chem. Lett. 23, 4648-4651. doi: 10.1016/j.bmcl.2013.06.011

Rondelez, Y., Tresset, G., Tabata, K. V., Arata, H., Fujita, H., Takeuchi, S., et al. (2005). Microfabricated arrays of femtoliter chambers allow single molecule enzymology. Nat. Biotechnol. 23, 361-365. doi: 10.1038/nbt1072

Sakakihara, S., Araki, S., Iino, R., and Noji, H. (2010). A singlemolecule enzymatic assay in a directly accessible femtoliter droplet array. Lab Chip 10, 3355-3362. doi: 10.1039/c0lc00062k

Sims, C. E., and Allbritton, N. L. (2007). Analysis of single mammalian cells on-chip. Lab Chip 7, 423-440. doi: $10.1039 / \mathrm{b} 615235 \mathrm{j}$

Taubes, G. (2008). The bacteria fight back. Science 321, 356-361. doi: 10.1126/science.321.5887.356

Teng, S. W., Mukherji, S., Moffitt, J. R., de Buyl, S., and O'Shea, E. K. (2013). Robust circadian oscillations in growing cyanobacteria require transcriptional feedback. Science 340, 737-740. doi: 10.1126/science.123 0996

Trouillon, R., Passarelli, M. K., Wang, J., Kurczy, M. E., and Ewing, A. G. (2013). Chemical analysis of single cells. Anal. Chem. 85, 522-542. doi: 10.1021/ac303290s

Vega, N. M., Allison, K. R., Khalil, A. S., and Collins, J. J. (2012). Signalingmediated bacterial persister formation. Nat. Chem. Biol. 8, 431-433. doi: 10.1038/nchembio.915

Wakamoto, Y., Dhar, N., Chait, R., Schneider, K., Signorino-Gelo, F., Leibler, S., etal. (2013). Dynamic persistence of antibioticstressed mycobacteria. Science 339 91-95. doi: 10.1126/science.122 9858

Weibel, D. B., Diluzio, W. R., and Whitesides, G. M. (2007). Microfabrication meets microbiology. Nat. Rev. Microbiol. 5, 209-218. doi: 10.1038/nrmicro1616
Yoshida, K., Nakayama, K., Ohtsuka, M., Kuru, N., Yokomizo, Y., Sakamoto, A., et al. (2007). MexABOprM specific efflux pump inhibitors in Pseudomonas aeruginosa. Part 7: highly soluble and in vivo active quaternary ammonium analogue D13-9001, a potential preclinical candidate. Bioorg. Med. Chem. 15, 7087-7097.

Zgurskaya, H. I., and Nikaido, H. (1999). AcrA is a highly asymmetric protein capable of spanning the periplasm. J. Mol. Biol. 285, 409-420. doi: 10.1006/jmbi.1998.2313

Conflict of Interest Statement: The authors declare that the research was conducted in the absence of any commercial or financial relationships that could be construed as a potential conflict of interest.

Received: 12 February 2013; accepted: 17 September 2013; published online: 04 October 2013.
Citation: Iino R, Matsumoto $Y$, Nishino $K$, Yamaguchi $A$ and Noji $H$ (2013) Design of a large-scale femtoliter droplet array for single-cell analysis of drug-tolerant and drug-resistant bacteria. Front. Microbiol. 4:300. doi: 10.3389/fmicb.2013.00300

This article was submitted to Antimicrobials, Resistance and Chemotherapy, a section of the journal Frontiers in Microbiology.

Copyright (C) 2013 Iino, Matsumoto, Nishino, Yamaguchi and Noji. This is an open-access article distributed under the terms of the Creative Commons Attribution License (CC BY). The use, distribution or reproduction in other forums is permitted, provided the original author(s) or licensor are credited and that the original publication in this journal is cited, in accordance with accepted academic practice. No use, distribution or reproduction is permitted which does not comply with these terms. 